\title{
Experimental Results with Hypothetical Evidences for Bexol as an Effective Inhibitor Corrosion of Mild Steel in Acidic Environment and Its Epoxy Coating Behavior
}

\author{
M. MENAGA ${ }^{1}$, D. NALINI ${ }^{2 *}$ and SOWMYA RAMKUMAR ${ }^{2}$ \\ 1,2Department of Chemistry, PSGR Krishnammal College for Women, Coimbatore -641004, \\ Tamil Nadu, India. \\ ${ }^{*}$ Corresponding author E-mail: nalini@psgrkcw.ac.in, nalinichemistry@gmail.com \\ http://dx.doi.org/10.13005/ojc/360321
}

(Received: February 12, 2020; Accepted: June 03, 2020)

\begin{abstract}
The inhibitive ability against mild steel corrosion of pharmacologically active compound Bexol towards acid was valued by gravimetric experiments and electrochemical experiments. The results of the weight loss studies indicated inhibition efficiency was boosted with increased concentration of Bexol from $5 \mathrm{mg} / \mathrm{L}$ to $45 \mathrm{mg} / \mathrm{L}$ in the acid environment. Potentiodynamic polarization behaviour of the metal specimen in presence of Bexol exposed the mixed style inhibitive action. EIS results established that Bexol adsorb at the metal/acid junction by mere electrostatic physical adsorption mechanism to inhibit the corrosion process. Epoxy coated mild steel without and with the studied bexol was used for electrochemical studies in $3.5 \%$ of $\mathrm{NaCl}$ for different time intervals. The Density Functional -theory was employed to scrutinize inhibition property of the considered inhibitor. Experimental measurement obtained shows perfect fit to the theoretical calculations.
\end{abstract}

Keywords: Mild steel, Bexol, Acid corrosion, EIS, DFT, epoxy coating.

\section{INTRODUCTION}

Compared to the higher carbon steels, mild steel have high tensile strength. Due to its mechanical properties of weldability and machinability and acid environmental stability mild steel is the main construction material ${ }^{1-4}$. One of the mechanical application of mild steel is its ferromagnetism. Making motor parts, electrical generators, electrochemical equipment, pole pieces etc., and ferromagnetism of mild steel is the primary component. $\mathrm{HCl}$ act as the major role for acidizing treatment compared to the other mineral acids because $\mathrm{HCl}$ forms metal chlorides, in aqueous phase these are very soluble. $\mathrm{HCl}$ is used for steel pickling, acid descaling, cleaning of boilers an industrial process ${ }^{5-7}$. Inhibitors ${ }^{8}$ are applied is the most effective method for control the metal dissolution.

Up to now, for preventing steel from corrosion, addition of some organic inhibitors is the most widely used and it is one of the most efficient method ${ }^{9-12}$. The inhibitive ability of organic compounds for metal corrosion is usually attributed

This is an Open Access article licensed under a Creative Commons license: Attribution 4.0 International (CC- BY). Published by Oriental Scientific Publishing Company @ 2018 
to their adsorption ability on metal surfaces, which can block the active sites on metal surfaces and thereby suppress the corrosion attack. Generally, the adsorption of organic molecule on metal surface depends mainly on the type of aggression medium, surface charge on the metal, the chemical structure of organic molecule etc. Heterocyclic organic compounds containing oxygen, nitrogen, sulfur, phosphorus and aromatic rings are the more efficient inhibitors for the metals in acidic medium ${ }^{3-15}$.

Nitrogen sulpher and oxygen containing organic compounds are well known acid inhibitors. These compounds efficiency is based on the feasibility of these molecules to get adsorbed on the solid surface with reactive center at the polar groups ${ }^{16}$. The function of the organic inhibitors, an active sites are blocked by displacing the water molecules and barrier film are formed. Some of the heterocyclic compounds are of curative importance and have been successfully tested with corrosive environment and gained much importance as well. Quaternary salts, alkylphenones, actylinic alcohol, aromatic aldehyde and some amines, carbonyls are acidizing inhibitors and which are commercially available. Nitrogen heterocycles have conventional more attention to drug chemistry due to their miscellaneous medicinal potential. These compounds are detrimental for environment and living organism due to their toxic and non-degradable. Therefore, current research is focused on development of non-toxic ecofriendly inhibitors ${ }^{17-20}$.

In the present student, a pharmaceutically active compound Bexol (Fig. 1) is an anticholinergic drug whose main component is trihexyphenidyl with a molecular formula $\mathrm{C}_{20} \mathrm{H}_{31} \mathrm{NO}$. The IUPAC name of the drug Bexol is 1-cyclohexyl-1-phenyl-3-piperidin1-yl propan-1-ol. The studied inhibitor stays non-toxic and easily available with a high molecular weight.

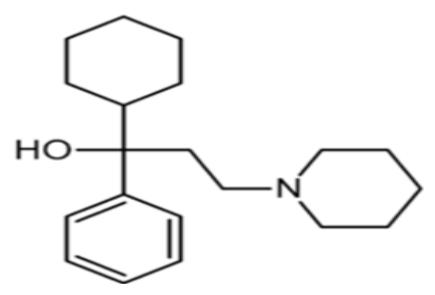

Fig. 1. Structure of Bexol

To the finest of our acquaintance Bexol stands not charity as inhibitor for acid corrosion. Thus this existing research deals with determining the effectiveness of Bexol as inhibitor for mild steel for its acid attack by experimental as well as quantum chemical studies. Also the epoxy coated mild steel behavior in $3.5 \%$ of $\mathrm{NaCl}$ was premeditated by electrochemical studies for different time duration ${ }^{21,22}$.

\section{EXPERIMENTAL}

\section{Materials}

The mild steel devising a configuration (weight percentage) of $0.098 \%$ C, $0.201 \% \mathrm{Mn}, 0.02 \%$ $\mathrm{P}, 0.016 \% \mathrm{~S}, 0.012 \% \mathrm{Ni}$, and $99.653 \% \mathrm{Fe}$. The mild steel coupons were expurgated into the measurement $5.00 \mathrm{~cm}$ length $\times 1.50 \mathrm{~cm}$ breath $\times 0.50 \mathrm{~cm}$ thickness for gravimetric measurements. For electrochemical measurements, mild steel rod of exposed surface area $1 \mathrm{~cm}^{2}$ while the remainder was embedded by teflon with $3 \mathrm{~cm}$ long stem following ASTM G 102-89 procedure ${ }^{23}$. Acid environment, $1 \mathrm{M} \mathrm{HCl}$ was prepared by using AR grade hydrochloric acid.

\section{Inhibitor preparation}

The testing solution of Bexol was prepared by dissolving it in the present acid solution and further diluted to different focuses (Bexol: $5-50 \mathrm{mg} / \mathrm{L}$, $15 \mathrm{mg} / \mathrm{L}, 30 \mathrm{mg} / \mathrm{L}, 45 \mathrm{mg} / \mathrm{L}, 50 \mathrm{mg} / \mathrm{L}, 55 \mathrm{mg} / \mathrm{L}, 60$ $\mathrm{mg} / \mathrm{L}$ ) of the inhibitor solution are prepared by dilution through double distilled water.

\section{Methods \\ Weight loss measurements}

Rectangular coupons of working surface area $5 \mathrm{~cm}^{2}$ were used for weight loss measurements following the standard ASTM G1-03 procedure ${ }^{24}$. Three MS plates that are already weighed were suspended in studied acid solution without and with Bexol (5-50 mg/L) for $3 \mathrm{~h}$ at $298 \mathrm{~K}$, respectively. Then the coupons were carefully cleaned and dried for removal of corroded particles and reweighed. From the weight loss extents, surface coverage $(\theta)$, inhibitor efficiency (IE\%) and rate of corrosion are calculated as given (Table 1).

$$
\begin{aligned}
& \mathrm{IE} \%=\frac{W-W i}{W} * 100 \\
& \text { Corrosion rate }\left(\text { mpy) }=\frac{534 * \mathrm{~W}}{\mathrm{D} * \mathrm{~A} * \mathrm{~T}} * 100\right.
\end{aligned}
$$

Where $\mathrm{W}$ and $\mathrm{W}_{\mathrm{i}}$ are the weight loss of the MS coupon without and with bexol.

Where, W -wass loss (mg), D -density of 
MS $\left(\mathrm{g} / \mathrm{cm}^{3}\right), A$-surface area of MS coupon (in $\left.{ }^{2}\right)$ and $\mathrm{T}$-Exposure time (h).

\section{Electrochemical measurements}

Electrochemical capacities were studied by IVIUM model 2723 electrochemical workstation ${ }^{25}$ with mild steel rod, saturated calomel electrode (SCE) and platinum electrode as a working electrode, reference and counter electrode respectively. Previous to each measurement, a stable state of open circuit potential (OCP) was obtained within 20 min of exposure of the working electrode in $\mathrm{HCl}$. Impedance measurements were done with $25 \mathrm{mV}$ amplitude from $100 \mathrm{KHz}$ to $0.01 \mathrm{~Hz}$. Polarization curves were analyzed at a scan rate of $100 \mathrm{mv}$ $\mathrm{s}^{-1}$ from-200 mV to $+200 \mathrm{mV}$ with respect to OCP. The I.E \% values are calculated from the following equation.

I. $E \%=\frac{\operatorname{Rct}(p)-\operatorname{Rct}(a)}{\operatorname{Rct}(p)} * 100$

Where $R_{c t}(p)$ and $R_{c t}(a)$ are the charge transfer resistance absence and presence of Bexol.

\section{Epoxy coating}

The fine powders of zinc $(2.675 \mathrm{~g})$, zinc phosphate $(1 \mathrm{~g}), \mathrm{TiO}_{2}(0.4287 \mathrm{~g})$ and the studied inhibitor $(0.1 \mathrm{~g})$ powers were mixed well. Epoxy resin (binder) is mixed with polyamide (hardener). Xylene is used a solvent. The prepared fine powder is added with epoxy resin-polyamide mixture and grain well and solvent is added drop by drop until the paint form was obtained. The obtained paint is coated on the mild steel surface. Then they were labelled as (A) the bare mild steel coupon without any coating (B) epoxy paint coated mild steel and (C) epoxy paint mixed with the inhibitor Bexol coated mild steel. The coated mild steel plates were dried in the laboratory at room temperature for 78 hours. The epoxy coated mild steel with a thickness of $2 \mathrm{~mm}$ coating were engrossed in $3.5 \%$ sodium chloride solution ${ }^{26}$.

\section{Electrochemical Measurements of the epoxy coating}

Electrochemical measurements stayed performed using NOVA autolab ${ }^{27}$ electrochemical system and electrochemical cell assembly of three electrodes using coated mild steel coupons is a working electrode (area of $5 \mathrm{~cm}^{2}$ ) exposed to $3.5 \% \mathrm{NaCl}$.

\section{Theoretical methods}

Complete optimized geometrical structure of the scrutinized inhibitor stood obtained by DFT with (B3LYP) procedure ${ }^{28}$ with the basics of 6-31G $(d, p)$ within the program package GAUSSIAN $09^{29}$. All the quantum chemical limits such local selectivity parameters as well as global parameters were calculated and discussed for Bexol.

\section{RESULTS AND DISCUSSION}

\section{Weight loss measurements}

The weight loss results obtained on mild steel coupons in $\mathrm{HCl}$ after $3 \mathrm{~h}$ immersion deprived of and by dissimilar concentrations $(5-50 \mathrm{mg} / \mathrm{L})$ of the studied inhibitor Bexol is presented in the Table 1.

From Table 1, it was seen that the corrosion rates diminution whereas inhibition efficiencies upsurge with incremental attention of the inhibitors ${ }^{30}$. The corrosion inhibitive assets for the inhibitor is recognized to the presence of electro rich centers ${ }^{31}$ that are the donor sites in the molecule which act as the blocking sites at the metal/acid junction. Thus inhibitor are adsorbed on the coordination mode between the electrons rich ${ }^{32}$ nitrogen atom of the piperidyl ring with the available orbital of the metal surface which act as a donor-acceptor surface complexes that act as protective barrier formed at the metal solution interface ${ }^{33}$ against acid attack on the metal.

Table 1: Effect of concentration on the inhibition of Bexol

\begin{tabular}{ccccc}
\hline $\begin{array}{c}\text { Conc } \\
(\mathrm{mg} / \mathrm{L})\end{array}$ & $\begin{array}{c}\text { Weight } \\
\text { loss } \\
(\mathrm{g})\end{array}$ & $\begin{array}{c}\text { Corrosion } \\
\text { rate } \\
(\mathrm{mpy})\end{array}$ & $\begin{array}{c}\text { Surface } \\
\text { coverage } \\
(\theta)\end{array}$ & $\begin{array}{c}\mathrm{IE} \\
(\%)\end{array}$ \\
\hline Blank & 0.0922 & 2697 & - & - \\
5 & 0.0716 & 2094 & 0.2234 & 22.34 \\
10 & 0.0689 & 2015 & 0.2527 & 25.27 \\
15 & 0.0549 & 1605 & 0.4046 & 40.46 \\
20 & 0.0519 & 1518 & 0.4371 & 43.71 \\
25 & 0.0438 & 1281 & 0.5249 & 52.49 \\
30 & 0.041 & 1199 & 0.5553 & 55.53 \\
35 & 0.024 & 702 & 0.7397 & 73.97 \\
40 & 0.0216 & 631 & 0.7657 & 76.57 \\
45 & 0.0141 & 412 & 0.8471 & 84.71 \\
50 & 0.0137 & 400 & 0.8514 & 85.14 \\
55 & 0.0108 & 315 & 0.8829 & 88.29 \\
60 & 0.0095 & 277 & 0.8969 & 89.69 \\
\hline
\end{tabular}




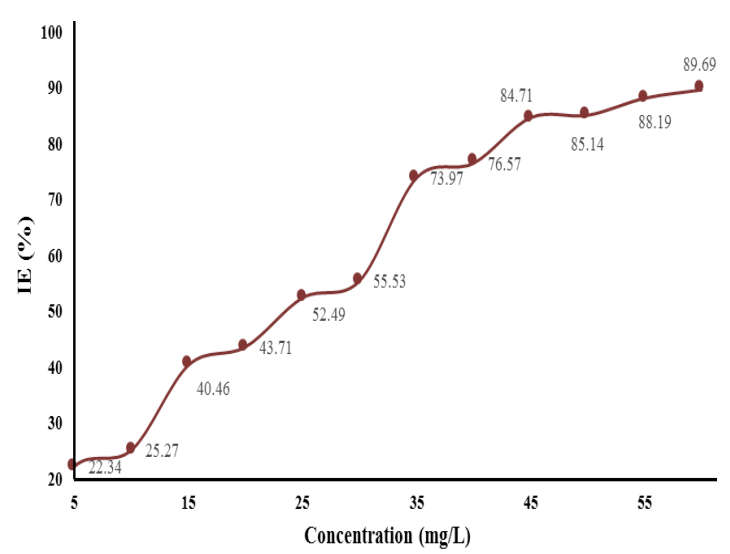

Fig. 2. Inhibitor attentiveness on the corrosion protection effectiveness in $1 \mathrm{M} \mathrm{HCl}$

Figure 2 represent the consequence of inhibitor concentration on the protection ability of Bexol on mild steel in acid medium. It was evidenced from the figure that the maximum inhibition efficiency of $84.71 \%$ reaches at $45 \mathrm{mg} / \mathrm{L}$ and with any further additionally increase in concentration up to $60 \mathrm{mg} / \mathrm{L}$, there was no considerable rise in the inhibition efficiency of Bexol. The I.E (\%) and surface coverage $(\theta)$ increases with rise in inhibitor concentration that is due to the growth in the thickness of the protective film at junction due to the adsorption of more inhibitor particle at higher concentration. At higher concentrations, due to the increase in the number of available molecules, there is an increase in the number of absorbed molecules on the metal surface which may lead to increased surface coverage and hence an increase in the IE\% by $8 \%$. The studies have been performed in the range of 5-60 mg/L inhibitor concentration. But after $45 \mathrm{mg} / \mathrm{L}$ concentration there is no significant increase in the inhibition efficiency (increases in decimals only). Hence $45 \mathrm{mG} / \mathrm{L}$ concentration is considered to be as optimum concentration of Bexol experiencing a higher efficiency. Thus the optimal concentration of Bexol for which maximum efficiency was found to be at $45 \mathrm{mg} / \mathrm{L}$ concentration for Bexol in $1 \mathrm{M} \mathrm{HCl}$.

\section{Potentiodynamic polarization measurements}

Tafel polarization curves for mild steel together with Bexol are shown in Figure 3.

The key polarization parameters derived as of these tafel curves and IE\% is calculated as follows Table 2.

$$
\text { I. } E \%=\frac{\operatorname{Rct}(p)-\operatorname{Rct}(a)}{\operatorname{Rct}(p)} * 100
$$

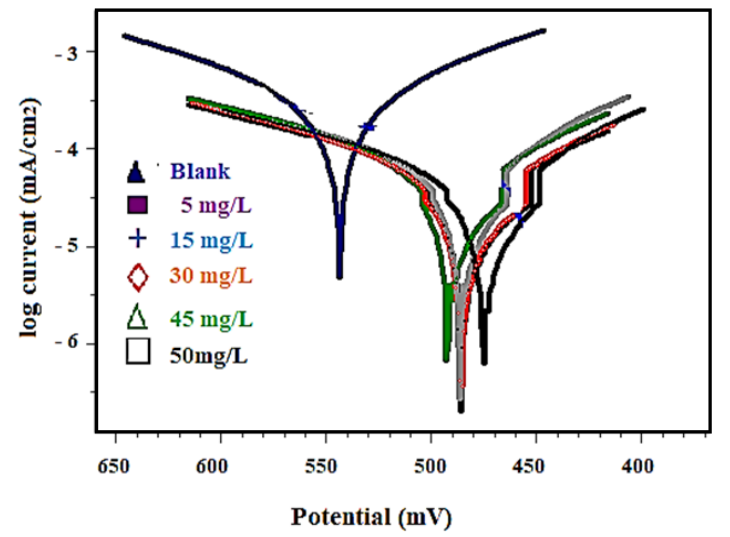

Fig. 3. Tafel polarization curves for mild steel together with Bexol

Table 2: Polarization parameters for mild steel without and with Bexol in $\mathrm{HCl}$

\begin{tabular}{cccccc}
\hline $\begin{array}{c}\text { Concentration } \\
\mathrm{mg} / \mathrm{L}\end{array}$ & $\begin{array}{c}\mathrm{I}_{\text {corr }} \\
\left(\mu \mathrm{A} / \mathrm{cm}^{2}\right)\end{array}$ & $\begin{array}{c}\mathrm{E}_{\text {corr }} \\
(\mathrm{mV})\end{array}$ & $\begin{array}{c}-\beta_{\mathrm{a}} \\
(\mathrm{mV} / \mathrm{dec})\end{array}$ & $\begin{array}{c}-\beta_{\mathrm{c}} \\
(\mathrm{mV} / \mathrm{dec})\end{array}$ & $\begin{array}{c}\mathrm{IE} \\
\%\end{array}$ \\
\hline Blank & 1609 & -424 & 55 & 121 & - \\
5 & 1267 & -524 & 106 & 103 & 21.26 \\
15 & 1036 & -519 & 99 & 111 & 35.61 \\
30 & 784 & -516 & 80 & 126 & 51.27 \\
45 & 248 & -509 & 79 & 132 & 84.57 \\
50 & 191 & -506 & 76 & 133 & 88.16 \\
\hline
\end{tabular}

The results revealed that with increasing inhibitor strength there is an appreciable reduction in $\mathrm{I}_{\text {corr }}$ owing to an rise in I.E (\%), signifying that Bexol affects electrochemical process that occurs at the mild steel surface. The environment of the Tafel curves is different in absence and presence of Bexol. This shows that the corrosion process after the addition of the Bexol follows a different mechanism. The presence of bexol causes a change in $\mathrm{E}_{\text {corr }}$ values with respect to its absence. If the corrosion potential differs more than $\pm 85 \mathrm{mV} / \mathrm{SCE}^{35}$ than that in the absence of the inhibitor then the nature of the inhibitor can be ascertained. In the present study, addition of bexol to $1 \mathrm{M} \mathrm{HCl}$ differs the $\mathrm{E}_{\text {corr }}$ value by more than $85 \mathrm{mV}^{36}$. This results reveals that the presence of Bexol, affect more of the anodic suspension of metal reactions than the cathodic hydrogen progress reaction. This interpretation is also evidenced from the greater shift in the tafel slope $\left(\beta_{\mathrm{a}}\right)$ value for the anodic reaction compared to the corresponding change in the cathodic tafel slope $\left(\beta_{b}\right)$. Thus, the studied inhibitor Bexol act as a predominant anodic inhibitor in $1 \mathrm{M} \mathrm{HCl}$. 


\section{Electrochemical impedance spectroscopic measurements}

Mechanistic insight into corrosion protection by Bexol in the corresponding medium can be studied by impedance analysis (EIS). The characteristic parameters of the double layer were obtained from the Nyquist plot (Fig. 4) is given in Table 3.

Table 3: Impedance parameters for corrosion of mild steel in $\mathrm{HCl}$ with Bexol

\begin{tabular}{cccc}
\hline $\begin{array}{c}\text { Concentration } \\
(\mathrm{mg} / \mathrm{L})\end{array}$ & $\begin{array}{c}\mathrm{R}_{\mathrm{ct}} \\
(\mathrm{ohm} \mathrm{cm})\end{array}$ & $\begin{array}{c}\mathrm{C}_{\mathrm{dl}} \\
\left(\mu \mathrm{F} / \mathrm{cm}^{2}\right)\end{array}$ & $\begin{array}{c}\text { Inhibition efficiency } \\
(\%)\end{array}$ \\
\hline Blank & 14 & 104 & - \\
5 & 18 & 26.4 & 22.2 \\
15 & 27 & 23 & 48.18 \\
30 & 47 & 26.4 & 70.21 \\
45 & 74 & 17 & 81.08 \\
50 & 89 & 18.2 & 84.26 \\
\hline
\end{tabular}

On analyzing the result obtained from Nyquist plot, it was noted that by means of the deliberation of the inhibitor increases $\mathrm{R}_{\mathrm{ct}}$ value remains increased ${ }^{37}$ and the $C_{d l}$ values are decreased ${ }^{38}$. This results revealed that there exists a productive cover at the M/S boundary which represents adsorption of Bexol arranged surface. The adsorption of the inhibitor on the electrode its electrical capacity decreases because water molecule are displaced by adsorbed Bexol, ${ }^{39}$ thereby decreases the $C_{d l}$ values due to growth of the double layer, suggesting adsorption of Bexol molecule on metal surface.

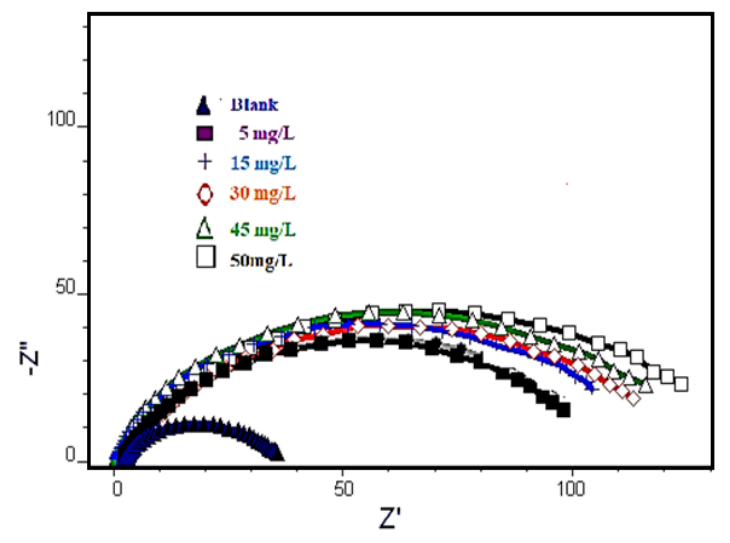

Fig. 4. Nyquist plots recorded on MS with Bexol

Thus with sustancial increase in the inhibitor attentiveness there is more adsorption of Bexol on the mid steel surface thereby increasing the thickness of the electrical double layer at the interface, as evidenced from the decline in the double layer capacitence with rise in charge transfer resistance.
Epoxy coating behavior of Bexol in $3.5 \%$ of $\mathrm{NaCl}$

Mild steel coating behavior mechanism is elaborately studied by electrochemical impedance spectroscopy and to elucidate in electrochemical system of transport phenomena and resolve mechanism of corrosion and rate. Nyquist and bode plots are the most famous output data format. The imaginary component $Z$ " is disappears at high frequency to allow only solution resistance Rs. At frequency is very low Z" is again disappears, cause to remain the sum of $R_{s}$ and polarization resistance $R_{p}$ or faradic reaction resistance and conversely proportional to corrosion rate. The results are obtained in the form of Nyquist plot as exposed in Fig. 5 besides the consistent impedance limits obtained were presented happening Table 4.

Table 4: Electrochemical limits obtained for epoxy coated mild steel in $3.5 \%$ of $\mathrm{NaCl}$

\begin{tabular}{cccc}
\hline Sample & $\begin{array}{c}\text { Solution } \\
\text { Resistance } \\
\mathrm{R}_{\mathrm{s}}\left(\Omega \cdot \mathrm{cm}^{2}\right)\end{array}$ & $\begin{array}{c}\text { Charge } \\
\text { Transfer } \\
\text { resistance } \\
\mathrm{R}_{\mathrm{ct}}\left(\Omega \cdot \mathrm{cm}^{2}\right)\end{array}$ & $\begin{array}{c}\text { Double Layer } \\
\text { Capacitance } \\
\mathrm{C}_{\mathrm{dl}}\left(\mu \mathrm{F} / \mathrm{cm}^{2}\right)\end{array}$ \\
\hline $\mathrm{A}$ & 9 & 0.77 & 90.0 \\
$\mathrm{~B}$ & 24 & 6.62 & 55.4 \\
$\mathrm{C}$ & 62 & 8.06 & 25.1 \\
\hline
\end{tabular}

The epoxy coating behavior of the pharmaceutically active compound Bexol (plate C) was studied in comparison with the epoxy coating in the absence of the inhibitor (Plate B) and also with bare polished mild steel plate (Plate A). Fig. 5 shows that Nyquist plot of sample A-C at different immersion time. In the impedance plot from the Fig. 5 (a) and (b), Sample $\mathrm{C}$ shows that at high frequency region only one capacitive arc is present, which is excellent property of the non-porous capacity of the coating. The electrochemical impedance behavior of the coating shows that considerable changes has taken place day 2 of immersion in $3.5 \% \mathrm{NaCl}$. Analysis of the impedance plots suggest that film effect ${ }^{40}$ is obtained by the high frequency loop. Sample C shows better fencing properties of coating and retard the perforation of the corrosive media into the surface of the substrate and delay the circumstance of corrosion reactions, which study the slow decrease in the impedance arc at low frequency region ${ }^{41}$ as seen in the Nyquist plot.

The important parameters as calculated as of Nyquist plot and presented in Table 4. From the Table 4 , the solution resistance $\left(R_{s}\right)$ of bare mild steel $(A)$ is $9 \Omega \mathrm{cm}^{2}$, paint coated mild steel (B) is $24 \Omega \bullet \mathrm{cm}^{2}$ and paint with Bexol coated mild steel (C) is $62 \Omega \bullet \mathrm{cm}^{2}$. The solution resistance $\left(R_{s}\right)$ was found 
to be more for the epoxy paint with Bexol coated mild steel $(C)$ compared to the others. The charge transfer resistance $\left(R_{c t}\right)$ of bare mild steel $(A)$ is 0.77 $\Omega \mathrm{cm}^{2}$, paint coated mild steel (B) is $661.9 \Omega \bullet \mathrm{cm}^{2}$ and paint with Bexol coated mild steel(C) is 805.5 $\Omega \bullet \mathrm{cm}^{2}$ is also found to be more for the inhibitor mixed epoxy coating for all the studied immersion time. And likewise double layer capacitance $\left(C_{d l}\right)$ diminutions as of bare mild steel (A) $90 \mu \mathrm{F} / \mathrm{cm}^{2}$, paint coated mild steel (B) $55.4 \mu \mathrm{F} / \mathrm{cm}^{2}$ and paint with Bexol coated mild steel $(C)$ is $25.1 \mu \mathrm{F} / \mathrm{cm}^{2}$ is increases.
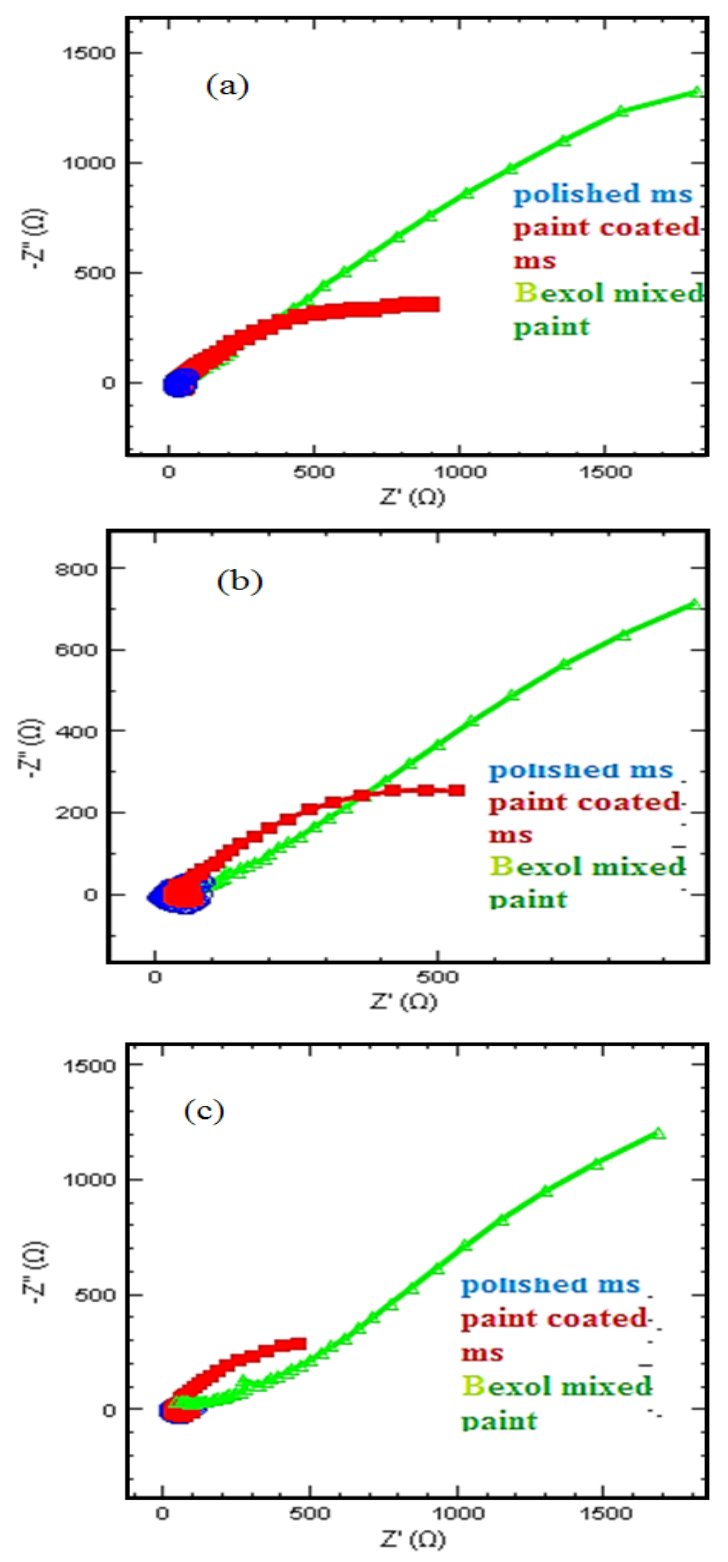

Fig. 5. Nyquist plots aimed at polished mild steel sample immersed in $3.5 \%$ of $\mathrm{NaCl}$ for (a) day 2 (b) day 4 (c) day
Potentiodynamic polarization studies in $3.5 \%$ of $\mathrm{NaCl}$

The potentiodynamic polarization curves illustrates that productive effect of the epoxy coating compared to that of polished mild steel plate in $3.5 \%$ of $\mathrm{NaCl}$. From the Table 5, the polarization parameters was noted.
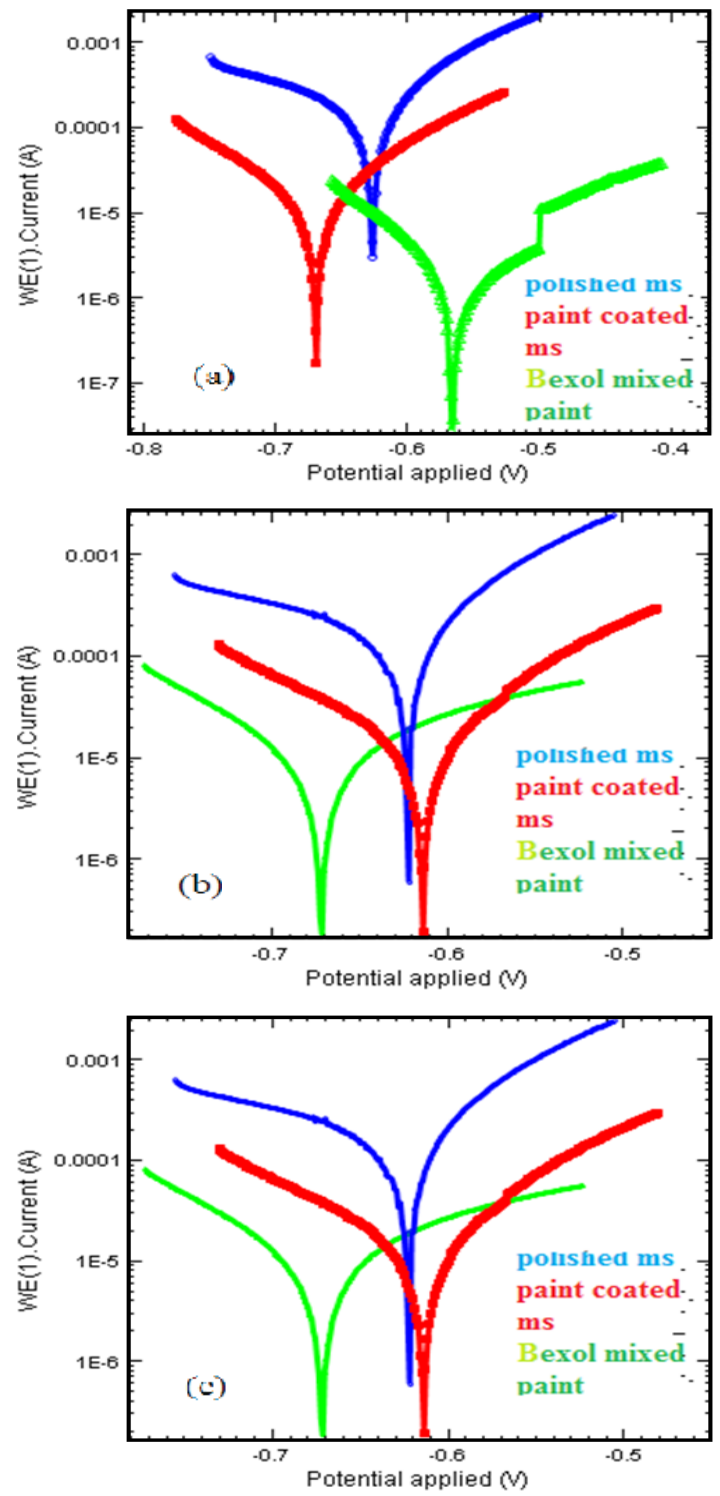

Fig. 6. Tafel curves for tepoxy coating behavior of Bexol immersed in $3.5 \%$ of $\mathrm{NaCl}$ for (a) day 2 (b) day 4 (c) day

Figure 6 shows that the calculate corrosion potential values shifted to lesser negative values compared to the bare uncoated mild steel and also the current values are smaller. This results suggest that mild steel surface coated with paint containing Bexol is more resistant to corrosion. 
Table 5: Potentiodynamic polarization curves for epoxy coated mild steel in $3.5 \% \mathrm{NaCl}$

\begin{tabular}{ccccc}
\hline Sample & $\begin{array}{c}-E_{\text {corr }} \\
(\mathrm{mV})\end{array}$ & $\begin{array}{c}\mathrm{I}_{\text {corr }} \\
\left(\mu \mathrm{A} / \mathrm{cm}^{2}\right)\end{array}$ & $-\beta_{\mathrm{a}}(\mathrm{mV} / \mathrm{dec})$ & $-\beta_{\mathrm{c}}(\mathrm{mV} / \mathrm{dec})$ \\
\hline $\mathrm{A}$ & 594 & 30.0 & 300 & 133 \\
$\mathrm{~B}$ & 602 & 10.8 & 318 & 111 \\
$\mathrm{C}$ & 677 & 6.2 & 202 & 129 \\
\hline
\end{tabular}

\section{Quantum chemical Studies}

Theoretical calculations were charity to harmonize the molecular structure of the investigated inhibitor. Fig. 7 represents optimized structure of the scrutinize Bexol inhibitor. The energies of Frontier molecular orbitals (EHOMO, ELUMO) are shown in Fig. 8(a) and 8(b) and interrelated to electron donating and accommodating ability of molecule.

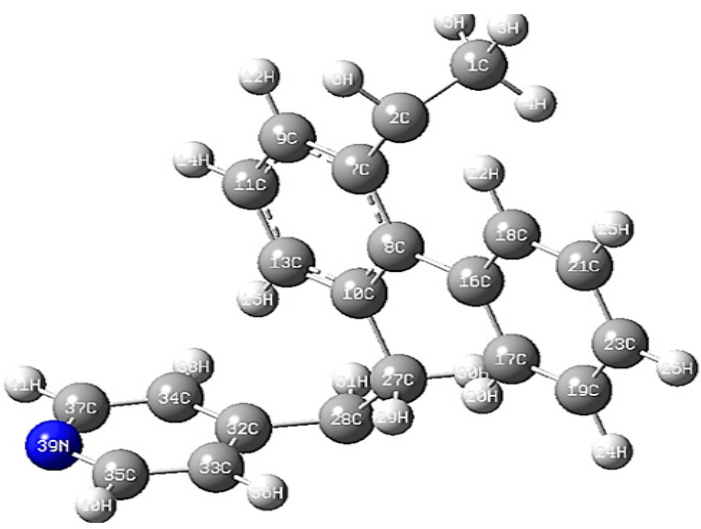

Fig. 7. Optimized structure of BEXOL

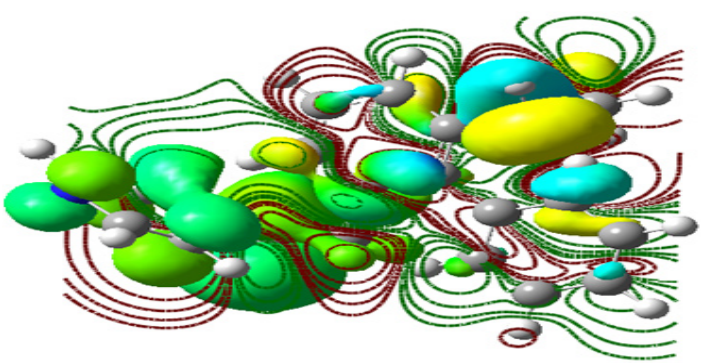

Fig. 8(a). HOMO of the BEXOL

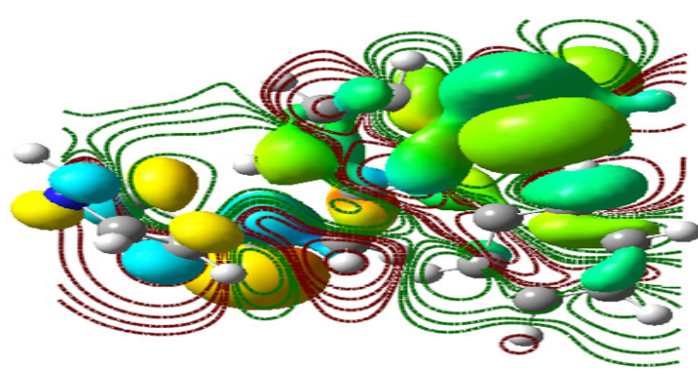

Fig. 8(b).LUMO of the BEXOL
Table 6: Quantum chemical parameters obtained by Gaussian 09

\begin{tabular}{lc}
\hline Quantum chemical Parameters & Bexol \\
\hline Molecular Formula & $\mathrm{C}_{20} \mathrm{H}_{31} \mathrm{NO}$ \\
Total Energy $(\mathrm{e} . \mathrm{v})$ & -855.52 \\
EHOMO $(\mathrm{e} . \mathrm{v})$ & -4.84 \\
ELUMO $(\mathrm{e} . \mathrm{v})$ & -2.13 \\
$\Delta \mathrm{E}(\mathrm{e} . \mathrm{v})$ & 2.71 \\
Dipole Moment $(\mu)$ & 10.177 \\
Global Hardness $(\eta)$ & 0.0497 \\
Global Softness $(\sigma)$ & 20.12 \\
Electronegativity $(\chi)$ & 0.1281 \\
$\Delta \mathrm{N}$ & 0.21 \\
\hline
\end{tabular}

High Energy of HOMO designate that the compound propensity to donate electrons ${ }^{42}$ to suitable acceptor. Lower energies of LUMO suggest the electron accepting character in the molecule ${ }^{43}$. From the studies, the obtained values of highest HOMO level -4.84 ev with lowest LUMO level $-2.13 \mathrm{eV}$, smaller value of $\Delta \mathrm{E}$ and greater value of dipole moment $(\mu)$ are characteristic features that are accountable for the adsorption characteristics. Table 6 clearly indicates that the maximum value of $\sigma(0.74), \Delta \mathrm{N}(0.21)$ proves the higher electron donating ability in Bexol. Conferring to Lukovis et al., if $\Delta \mathrm{N}$ is less than 3.6 the efficiency rises with electron donating. Now our present study $\Delta \mathrm{N}$ value is 0.21 . Obtained experimental consequences are in good agreement with the investigational findings.

\section{CONCLUSION}

The following results were analyzed for the inhibitive nature of a pharmaceutically active compound Bexol towards acid corrosion.

1. Studied inhibitor has admirable efficiency for corrosion at an optimum concentration of 45 $\mathrm{mg} / \mathrm{L}$ in $\mathrm{HCl}$.

2. Polarization revisions exposed bexol to be anodic type inhibitor.

3. Results from EIS experiment shows that the incorporation of Bexol with paint leads to the improvement in the performance of coating.

4. Potentiodynamic polarization results suggest that good antipermiability resistance. Theoretical studies, made using the DFT 
method, were used to gain more information nearby the reactivity of the Bexol as corrosion inhibitor. Calculation of the HOMO, the energy gap $\Delta \mathrm{E}$ and the segment of electron transfer $\Delta \mathrm{N}$ demonstrated that Bexol have a good inhibitive efficiency.

\section{ACKNOWLEDGEMENT}

The authors acknowledge the institution PSGR Krishnammal College for Women for the necessary facilities provided.

\section{Conflict of Interest}

All authors declare no conflict of interest.

\section{REFERENCES}

1. Fouda, A.S.; Rashwan, S. M.; Shaban, S.M.; Ibrahim, H.E; Elbhrawy, M.F.; Egypt. J. Pet., 2018, 27, 295-306.

2. Ongun Yüce,A.; Doru Mert,B.; Kardas,G.; Yazici,B.; J. Corros. Sci., 2014, 83, 310-316.

3. Boumhara, K; Bentiss, F; Tabyaoui, M; Costa, J; Desjobert, J.M; Bellaouchou, A; Guenbour, A; Hammouti, B; Al-Deyab, SS; Int. J. Electrochem. Sci., 2014, 9, 1187-1206.

4. Helen, L.Y.S,; Rahim, A.A,; Saad, B,; Saleh, M.I,; Raja,P.B, Int. J. Electrochem. Sci., 2014, 9, 830-846,

5. Goyal, M,;Kumar,S,;Bahadur,l;;Verma, C,;Ebenso, E.E, J. Mol. Liq., 2018, 256, 565-573,

6. Kumar, S.; Sharma, D.;Yadav, P.;Yadav, M,' J. Ind. Eng. Chem. Res., 2013, 52, 14019-14029.

7. Fuchs-Godec, R.; Pavlovic, M.G.;Tomivc, M.V, Ind. Eng. Chem. Res., 2012, 51, 274-284,

8. Verma, C.;Chauhan, D.S.; Quraishi, M.A, J. Mater. Environ. Sci., 2017, 8, 4040-4051.

9. Obot, I.B.; Macdonald, D.D.; Gasem, Z.M, J.Corros. Sci., 2015, 99, 1-30.

10. Eldesoky, A.M.; Diab, M.A.;El-Bindary, A.A.; El-Sonbati, A.Z.; Seyam,H.A, J. Mater. Environ. Sci., 2015, 6, 2148-2165.

11. Patel, A.S.; Panchal,V.A .; Mudaliar, Shah, N. K, J. Saudi Chem. Soc., 2013, 17, 53-59,

12. Chakravarthy,M.P.; Mohana, K.N.; ISRN Corros., 2014, 1-13.

13. Mangai, S.A.; Ravi, S, J. Chem., 2013, 2013, 1-5.

14. Gurudatt D.M.; Mohana,K.N, J. Ind. Eng. Chem. Res., 2014, 53, 2092-2105.

15. Tian, H.; Cheng, Y.F.; Li, W.; Hou, B, J.Corros. Sci., 2015, 100, 341-352.

16. L. L. Liao, L.L,; Mo, S,; Luo, H.Q,; Feng, Y.J; Yin, H.Y,; Li, N.B, J.Corros. Sci., 2017, 124, 167-177.
17. Y. Qiang, S. Zhang, L. Guo, X. Zheng, B. Xiang, and S. Chen,"J. Corros. Sci., 2017, 119, 68-78.

18. H. Sachdeva,H.; R. Saroj,R.; Dwivedi, D.; Sci World J., 2014, Article ID 427195,1- 10.

19. Khadraoui, A.; Khelifa,A.; Boutoumi, H," no. January., 2015.

20. Yadav,M.; Behera,D.; Kumar,S.; Sinha, R, R, J. Ind. Eng. Chem. Res., 2013, 52, 6318-6328.

21. Mirzakhanzadeh,Z.; A. Kosari,A; M. H. Moayed,M.H.; R. Naderi,R.; Taheri,P.; Mol, J. M. C, J.Corros. Sci., 2018, 138, 372-379.

22. Pourriahi,M.; Nasr-Esfahani, M.;Motalebi.A, J. Surf. Eng. Appl. Electrochem., 2014, 50, 525-533.

23. ASTM G 102-89, Standard practice for calculation of corrosion rate and related information from electrochemical measurements, ASTM International, West Conshohocken, PA 2010, www.astm.org.

24. ASTM G1-03, Standard Practice for Preparing, Cleaning, and Evaluating Corrosion Test Specimens, ASTM International, West Conshohocken, PA, 2003, www.astm.org.

25. Preethi Kumari, P.; Shetty, P.; and Rao, S. A.; Arab. J. Chem., 2017, 10, 653-663.

26. Goyal,M.; Kumar, S.; Bahadur, I.; Verma, C and Ebenso, E. E.; J. Mol. Liq., 2018, 256, 565-573.

27. Verma, C.; Chauhan, D.S.; and Quraishi,M.A .; J. Mater. Environ. Sci., 2017, 8, 4040-4051.

28. Nikpour, B.; Ramezanzadeh, B.; Bahlakeh,G.; and Mahdavian, M.; Corros. Sci., 2017, 127, 240-259.

29. Ganapathi Sundaram, R and Sundaravadivelu, M.; Egypt. J. Pet., 2018, 27, 95-103. 
30. Ramya,K.; Mohan,R.; and Joseph,A.; J. Mater. Eng. Perform., 2014, 23, 4089-4101.

31. Salhi,A.;Tighadouini,S.;El-Massaoudi,M.; Elbelghiti,M.;.Bouyanzer,M.; Radi,S.;.El Barkany, S.;Bentiss,,F.; Zarrouk, A., J. Mol. Liq., 2017, 248, 340-349.

32. Zaštita, Mater., 2012, 53, 15-28,

33. Mater. Chem. Phys., 2016, 177, 266-275.

34. Sounthari, P.; Kiruthika,A.; Chitra,S.; Parameswari,K.; and T. Nadu., 2013, 2, 25-40.

35. Pourriahi, M.; Nasr-Esfahani, M.; and Motalebi,A.; Surf. Eng. Appl. Electrochem., 2014, 50, 525-533.

36. Hao,Y.; Sani,L.A.; Ge, T.; Fang, Q.;" Corros. Sci., 2017, 123, 158-169.
37. Albrakaty, R.H.; Wazzan, N.A.; Obot, I.B.; Int. J. Electrochem. Sci., 2018, 13, 3535-3554.

38. Nwankwo,H.U.; Olasunkanmi,O.; Ebenso,E.E.; Sci. Rep., 2017, 7, 1.

39. Noor El-Din M.R.; Khamis,E.A.; J. Surfactants Deterg., 2014, 17, 795-805.

40. Ameh.P.O.; and Eddy, N.O.; Res. Chem. Intermed., 2014, 40, 2641-2649.

41. Samide.A.; and Tutunaru, B., Cent. Eur. J. Chem., 2014, 12, 901-908.

42. Mangai,S.A.; and Ravi,S.; J. Chem., 2013, 2013, 1-5.

43. El-Hajjaji, F.; Messali, M.; Aljuhani, A.; Aouad, M. R.; Hammouti, B.; Belghiti, M.E.; Chauhan, D. S.; Quraishi, M. A, J. Mol. Liq., 2018, 249, 997-1008. 